\title{
Web Design Curriculum and Syllabus Based on Web Design Practice and Students' Prior Knowledge
}

\author{
Tanja Krunić, Ljiljana Ružić-Dimitrijević, \\ Branka Petrović, and Robert Farkaš \\ The Advanced Technical School, Novi Sad, Serbia \\ krunic@nspoint.net ljaga@eunet.yu \\ b.petrovic@neobee.net Fx.aries@eunet.yu \\ Executive Summary
}

The Advanced Technical School from Novi Sad set up a completely new study group for web design in 2004. The main goals of the paper are to explain the steps that were taken in starting this group, and to present the educational program based on our own research through the organization of the group and course descriptions.

Since there is a growing need for all kinds of IT specialists, particularly in web design due to the development of the Internet, we concluded it was necessary to found such a study group. At the time when it was established, there were not many similar groups in the world exclusively dealing with web design, which means there were few suitable programs that could serve as examples. Consequently, research on student prior knowledge was carried out to select and create appropriate courses. It was essential to check in advance what could be expected from our freshmen in order to avoid possible mistakes in designing the program.

We tested 55 students of graphic design to see the status of their prior knowledge in web design. The reason why we chose this study group for testing was their interest in the WWW and designing for the Web. The test contained 28 questions regarding different web issues. They covered areas like usability, user-oriented web design, accessibility, privacy and security, which are briefly discussed in the paper. Although most of the students regularly used the Internet, they knew very little about these items. The obtained results enabled us to write the curriculum and syllabus for the group that included courses covering all these things.

Two documents were made so as to provide learners with a combination of technical and artistic aspects of the web designing process in all its phases. Websites that have aesthetic values are more attractive and definitely contribute to the development of taste. Therefore, a good balance

Material published as part of this journal, either on-line or in print, is copyrighted by the publisher of the Journal of Information Technology Education. Permission to make digital or paper copy of part or all of these works for personal or classroom use is granted without fee provided that the copies are not made or distributed for profit or commercial advantage AND that copies 1) bear this notice in full and 2) give the full citation on the first page. It is permissible to abstract these works so long as credit is given. To copy in all other cases or to republish or to post on a server or to redistribute to lists requires specific permission and payment of a fee. Contact Editor@JITE.org to request redistribution permission. between courses offering technical knowledge and skills and those educating web artists is highly important.

When creating educational programs in fields dealing with new technologies, especially if there is a lack of existing models, it is significant to examine students' prior experience and knowledge. The results of such investigations must be taken into account in order to determine standards 
that should be achieved, and to produce high quality programs. We believe that our curriculum and syllabus presented in this paper can be used as useful illustrative examples by those intending to start a similar study group.

Keywords: Web design study group, curriculum, syllabus, web issues, prior knowledge

\section{Introduction}

This paper deals with the way we started our web design study group. The main objective is to explain the procedure we used to test the students' prior knowledge of web design. Secondly we would like to present the educational program in this field based on our research.

The World Wide Web is nowadays part of our lives. When trying to create functional and attractive sites, web designers meet with difficulties because web design is associated with many other modern disciplines. Besides an extensive knowledge of new web design technologies, the designer should be familiar with usability, accessibility, privacy, and security. We must not, however, forget the artistic aspect of web designing - students ought to study subject areas such as graphic design, form and style, and drawing and painting.

Our survey of curricula from several universities worldwide (see: Additional sources) has shown that web design is not usually found as a separate study group. It is present as one or more courses within other study groups in computer science or information technology departments. Furthermore, the majority of the reviewed courses regarding the Web are mainly based on studying web technologies, programs, and scripts, neglecting the issues mentioned above. Our study group for web design was founded at the Advanced Technical School, Novi Sad in 2004 with an appropriate undergraduate program involving the fundamental knowledge of the abovementioned areas.

The world tendency to do business and a variety of other activities on the Web increases the need for special web design study groups. So, undergraduate studies aiming to educate future web design professionals should be harmonized with modern expectations in order to provide students with knowledge and skills necessary to deal with the complete situation on the Web. Therefore, curriculua and syllabuses should be made according to the needs of the present-day web community and the prior knowledge of students. Since the WWW influences our views regarding the standards of beauty among other things, it is important to educate designers who will be able to contribute to the development of aesthetics in general.

\section{Important Web Issues}

Let us first discuss some of the previously mentioned important areas connected with web design.

\section{Usability}

As mentioned earlier, the number of people relying on the WWW in their work is rising. Naturally, visitors expect to find useful sites to do business as fast and as comfortably as possible; therefore, usability, which is defined as the visitor's ability to use the site appropriately, is very important. Unfortunately, there are numerous websites with mistakes against usability, since they are partly unusable for the average user. The most common mistakes against usability can be found in Nielsen (2003). A user investigation in 2004 ("Web usability - the main rules", 2004 ) shows that about $40 \%$ of users never come back to a website after their first unsuccessful attempt. The most common reasons for their disappointment with websites can also be found in this investigation.

According to Powell (2000), the main web design aspects are purpose, web content, visual elements, and technologies. The basic principle of good web design is a balance between these four 
aspects, and the designer-to-user correspondence. However, a lot of websites are created without a previously defined purpose. Usually the only motive for their creation is just a reaction to the competition's website. On the other hand, sites with no balance between their function and form can be found on the Web every day. The same source claims the main reasons for this problem are the web designer's inexperience, short deadlines, and the so-called ad-hoc design without adopting any web design models. We believe that these problems occur due to the fact that web design courses are mostly focused on technologies, programs and scripts, as mentioned before.

\section{User-oriented Web Design}

One of the worst web designer's mistakes is to create a website without a previous analysis of user needs. Such websites may seem interesting and well designed to their authors, but they are complicated and almost useless for many visitors. Web designers should know that they are to create sites for users, not to show off their web technology knowledge. Therefore, it is advisable to interview users and make an appropriate selection of their desires, for some of them may be unrealistic. The web designer has to decide if user wishes can be met or not. This is very important since the designer is supposed to have a complete control over the situation at every moment. After its publishing, user opinions on a website should be monitored constantly.

\section{Accessibility}

Another problem to the web designer to deal with is accessibility. The World Wide Web Consortium (W3C) defines a website as accessible if it allows access to people with some kind of disability (W3C, 2005). The importance of accessible web design can be realized by analyzing the number of disabled people worldwide. A report (U.S. Census Bureau, 1997) categorizes $19.6 \%$ of the U.S. population as having some sort of disability. A detailed categorization of human disabilities influencing web design can be found in "Introduction to Web Accessibility" (Web Accessibility in Mind, 1998). Another source is the statistic about visually impaired people in the European Union, for example for people in Germany ("Statistics about visually impaired", 1994).

The Web Content Accessibility Guidelines (WCAG) (W3C, 1999) by the W3C was the first major effort to establish instructions for accessible design. This standard consists of fourteen guidelines, each with three checkpoint levels to be reached by web designers. Priority 1 checkpoints ensure that the page itself is accessible. Priority 2 checkpoints ensure that certain groups will be able to access information on the web page. Priority 3 checkpoints ensure that all content on the page is completely accessible (See also the Curriculum for Web Content Accessibility Guidelines (W3C, 2000)). In specific countries, national standards emerged later. Section 508 of the Federal Rehabilitation Act in the U.S. is based on WCAG Priority 1. Common Look and Feel in Canada (Adaptive Computer Technology Training Center, 1999) and Web Guidelines (2005) in the United Kingdom are based on Priorities 1 and 2 from the WCAG. The W3C provides an extensive listing of national standards initiatives.

Apart from the fact that it is obligatory in websites of many governments, accessibility should be widely spread in web designing because it opens the door to information for individuals with disabilities. In addition, all users benefit from accessible web design by getting more usable websites. It is based on up-to-date architecture and design that allow greater flexibility across the site. Accessibility also contributes to a growing market for software, hardware, and web design.

But, how much is web accessibility respected in practice? The authors of this paper tested the accessibility of 50 websites using WebEXACT, the free online service for testing accessibility of web content (http://webxact.watchfire.com/) and the results are given in Table 1. To be representative and independent, the test was performed in the following manner: Arbitrary terms were chosen from the English vocabulary and typed as keywords in a search engine. To represent the 
average accessibility situation worldwide, we chose several arbitrary web addresses with different country-coded Top-Level Domains from a results listing. Then the websites were tested by using WebEXACT.

Table 1: Results of the web accessibility test

\begin{tabular}{|c|c|c|}
\hline \multicolumn{3}{|c|}{ Percentage of websites satisfying } \\
\hline Priority1 & Priority2 & Priority 3 \\
\hline $34 \%$ & $0 \%$ & $6 \%$ \\
\hline
\end{tabular}

As we can see from Table 1, only $34 \%$ of the tested pages satisfy Priority 1 checkpoints meaning that almost $66 \%$ of the disabled people have no access to these pages. A completely accessible website, satisfying all checkpoints was not found in our research. Since a relatively small number of websites was examined, our aim is to widen the accessibility investigation in the future. Although we cannot make global conclusions, the obtained results can still be used as a parameter pointing to the necessity to improve accessibility in practice.

\section{Privacy}

User confidence is an important issue to companies. Unfortunately, the privacy of many web visitors is jeopardized due to data collecting on pages especially when the GET method of form submission is used, as it is known for its privacy vulnerabilities, and visitor tracking through cookies and web beacons.

A cookie is a file created by a website to store information on the user's computer, like preferences regarding the time when that particular site is visited (Microsoft, 2005). Cookies can store personally identifiable information that can be used to contact visitors, such as e-mail, home and work addresses, or telephone numbers. There are so-called first-party cookies and third-party cookies. First-party cookies are those left on your machine by the web page you are currently viewing. These cookies are commonly used to store information, e.g. favorite Web visiting hours. Third-party cookies are those left on your machine by a domain other than the one you are currently viewing. For instance, a lot of sites have advertisements from third-party websites and the latter may use cookies. Their common usage is to track the visitor's web preferences for advertising or marketing purposes.

Generally, a web beacon consists of a small string of code that represents a graphic image request on a web page or e-mail ("Web beacon," 2003). There may or may not be a visible graphic image associated with the web beacon and often the image is designed to blend into the background of the web page or e-mail. Web beacons may be delivered from the same or a different domain than the web page or e-mail viewed. They may be used by the party responsible for the web page or email viewed (first-party web beacons) or by the third-party (third-party web beacons).

A privacy statement is frequently insufficient to gain user confidence. The World Wide Web Consortium developed the Platform for Privacy Preferences Project (P3P 1.0, 2003), creating a simple, automated way for users to have more control over the use of personal information in websites they visit. Its basic level, P3P is a standardized set of multiple-choice questions covering all major aspects of the website's privacy polices. Taken together, they present a clear snapshot of how the site handles personal information about its users. P3P enables websites to make this information available in a standard, machine-readable format. It also enables browsers to "read" this snapshot automatically and compare it to the consumer's own set of privacy preferences. P3P enhances user control by putting privacy polices where users can find them, in the form users can understand, and, most importantly, enables users to act on what they see. Any organization wish- 
ing to increase user confidence should consider implementing P3P ("Why Implement P3P?" 2002).

During the accessibility investigation, we also examined privacy issues of the tested websites. The results clearly state that there are more websites with some sort of user tracking (32\%), than those using $\mathrm{P} 3 \mathrm{P}(8 \%)$. Hence, the need to promote user privacy in practice is great.

\section{Security}

E-business gives a chance to enlarge company profit and market share, and make new partnerships worldwide. But e-business is associated with a big risk of losing data and user confidence. However, a lot of companies neglect the need to secure information and regard it as waste of time and money. Consequently, they are at risk to lose much more money than is necessary to secure their data system. New computer worms are created every day. Since information travels over the Internet passing through several websites on its way from the sender to the receiver, hackers have a chance to catch the message and change or steal its content. To understand the need of data securing, we will mention the fact that due to computer virus attacks companies worldwide lost US\$ 123 million in 2004 ("New Viruses," 2005). An example of consequences of a hacker-driven web attack on an Australian bank database in 2001 can be found in Wolley \& Young (2001).

Hackers commonly use software vulnerabilities, and information related to them can be found on the Internet. Therefore, it is important to be informed about the vulnerabilities of company software. Relevant data can be retrieved from the cert-org website ("Vulnerabilities, incidents and fixes," 2005), for instance. Furthermore, software should be updated regularly. Web designers should be familiar with the use of firewalls, secure web page creating by means of client certificates, and many other related topics (Krunic \& Ruzic-Dimitrijevic, 2005). It is also very important for companies to hire website security administrators to look after their information systems.

A lot of companies and organizations create security polices - a set of behavior rules employees have to respect in order to increase data security (U.S. Department of Health and Human Services, 2002 ). Security policies are based on ISO/IEC 1779 standard concerning data security (ISO 1799 standard, 2000). A good source about web security and security polices is (AEB Web Security Guidelines, 2002). An example of the security police of UC Berkeley can be found in MacFadden \& Katagiri (2003). Since a web attack can happen in spite of all applied security measures, it is advisable to perform data backup daily. The stored data can be recovered in case of a successful attack. Yet all companies dealing with e-business should be prepared for web attacks and have a plan for data recovering and getting back into business.

\section{The Students' Prior Knowledge Analysis}

When the decision was made to start our web design study group, a set of questions was created based on a preliminary list of subjects and available references. According to the information gathered from these sources and investigations carried out in the latter, we selected valid questions from the initial set. Then the test was given to the first year students of graphic design in our School during their computing class. Finally, the obtained data was statistically analyzed on a computer.

We tested 55 students aged $18-20$, and the relation between boys and girls was 30:25. They had all completed secondary school and had computing as a subject. Approximately $90 \%$ of them were computer owners, which means they belonged to the middle class.

Since most students use the Internet every day and a lot of data about web design is available on the Web, the curriculum planers for the new web design study group tested the students' prior knowledge to check the relevancy of the appropriate curriculum and syllabus. The results were 
an important source of information in composing the curriculum. The test done by the freshmen contained 28 questions about web design. In order to increase the test relevancy, questions from different areas like basic web design knowledge, usability, accessibility, privacy, and security were mixed not grouped according to topics. The results reflecting the knowledge of specific web areas are given in Table 2 .

Table 2: Students' prior knowledge analysis

\begin{tabular}{|c|c|c|c|} 
& $\begin{array}{c}\text { Number of } \\
\text { questions }\end{array}$ & $\begin{array}{c}\text { Average number of correctly an- } \\
\text { swered questions }\end{array}$ & Percentage \\
\hline $\begin{array}{c}\text { Basic web design } \\
\text { knowledge }\end{array}$ & 6 & 1.24 & $20.7 \%$ \\
\hline Accessibility & 4 & 0.91 & $22.7 \%$ \\
\hline Usability & 11 & 2.71 & $24.6 \%$ \\
\hline Privacy & 1 & 0 & $0 \%$ \\
\hline Security & 6 & 0.56 & $9.3 \%$ \\
\hline Total & 28 & 5.42 & $19.4 \%$ \\
\hline
\end{tabular}

The complete list of questions can be found in Appendix 1. Now we will present only a few that were not answered correctly by most students.

A very important usability issue is to mark hyperlinks with the color blue, since visitors expect blue to indicate hyperlinks, but students did not realize the importance of this rule, Figure 1.

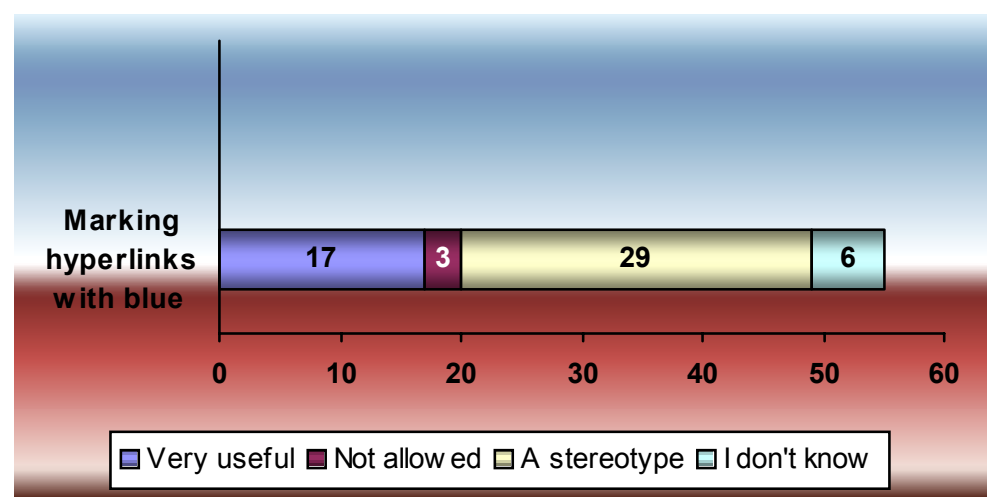

Figure 1: Students' opinion on marking hyperlinks

Figure 2 tells us that students knew nothing about accessible design, since none of them gave the right answer. 


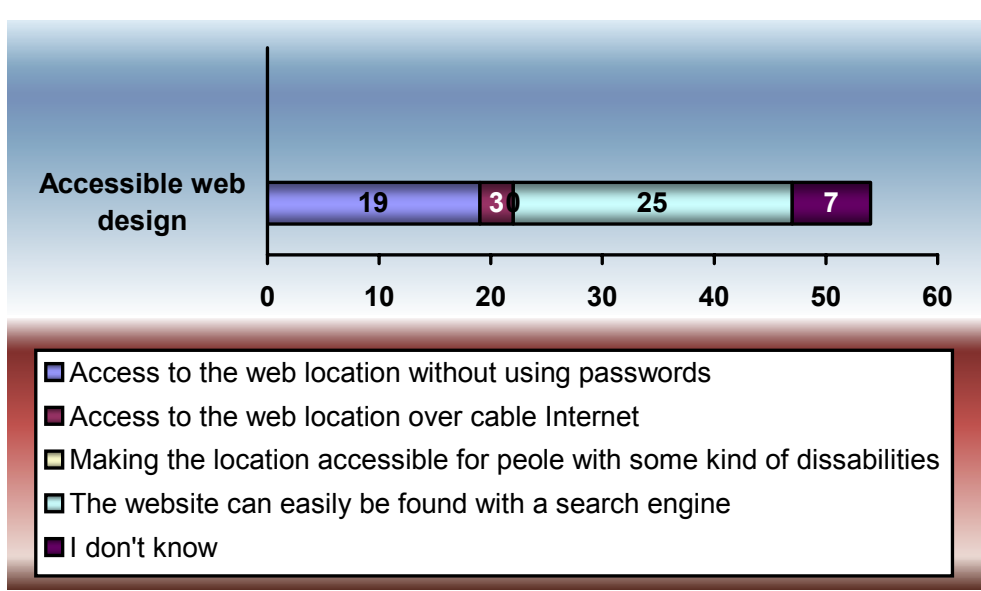

Figure 2: Students' opinion on accessible web design

Consequently, they had no information about screen readers and head pointers as assistive technologies used by people with disabilities, see Figure 3. The fact that their total knowledge about accessibility was $22.7 \%$ can be explained by the nature of the test consisting of multiple-choice questions, so some of them just guessed the correct answer.

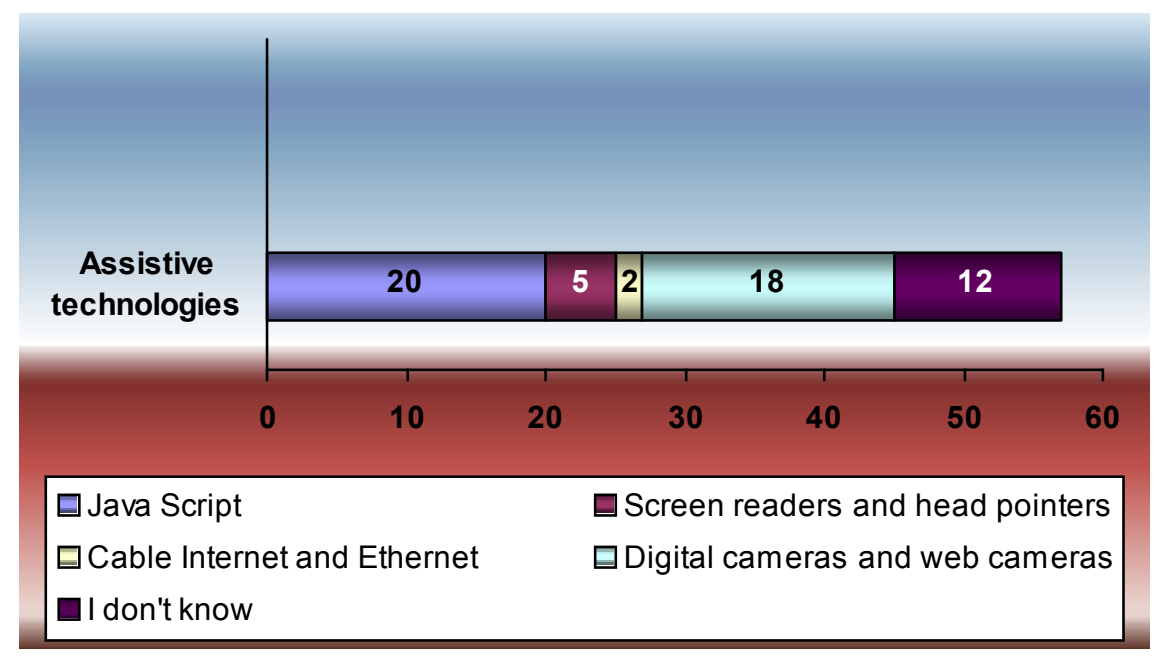

Figure 3: Students' opinion on assistive technologies

Another frequent mistake was related to the question about the security policy. As we can see from Figure 4, only 4 students answered it correctly. 


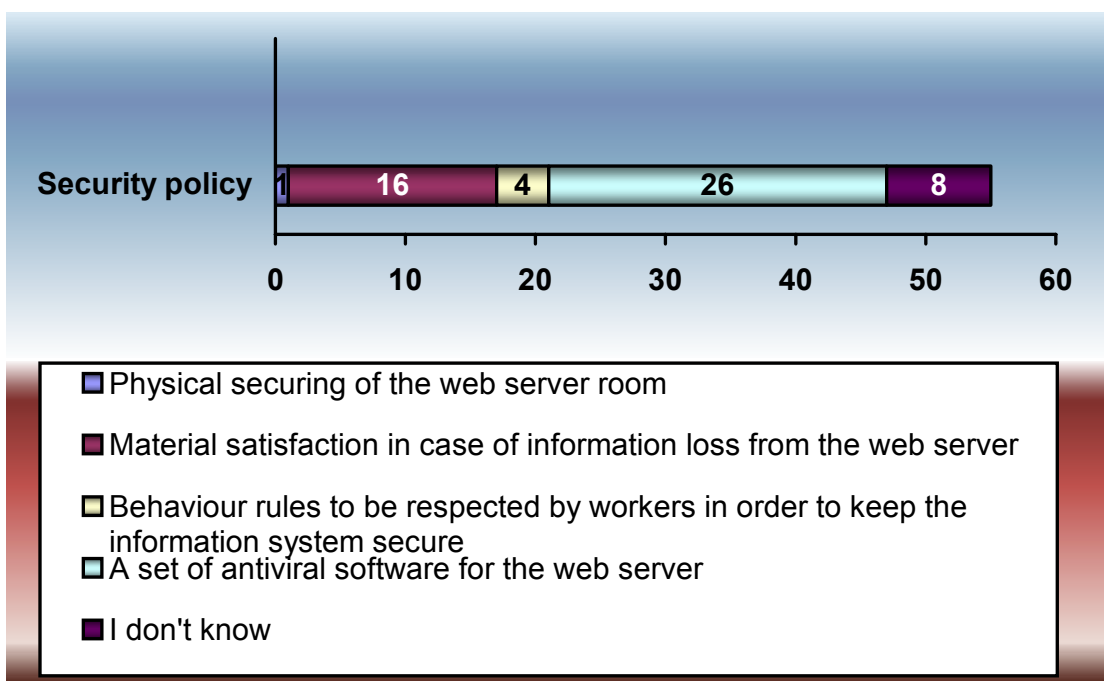

Figure 4: Students' opinion on security policy

It is also interesting that only a small group of students knew the fact that information travels over the Internet from the sender's computer to the receiver's computer through a dozen locations, Figure 5.

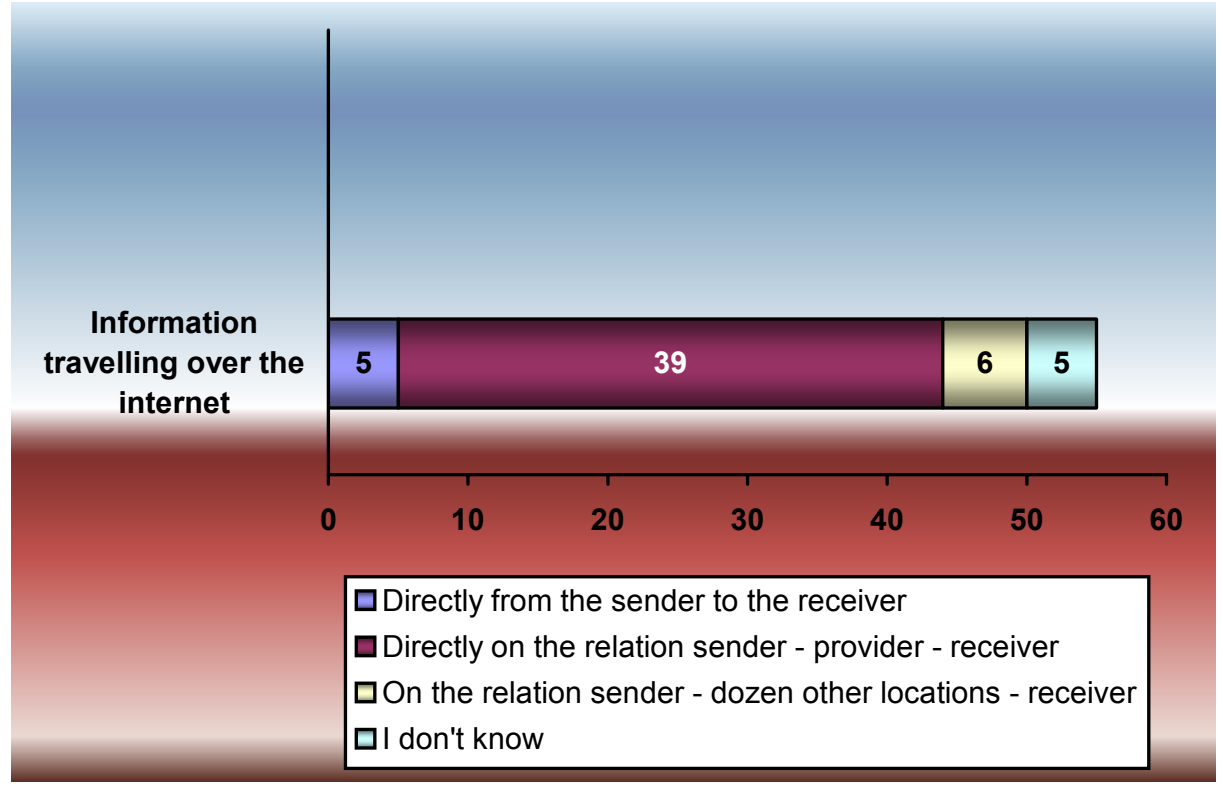

Figure 5: Students' opinion on information traveling over the Internet

None of the students had heard about P3P, and just three knew the full name of the W3C. Another interesting fact is that $69.1 \%$ of them did not know anything about what parts of the website ought to be verified before its publishing, and only $3.63 \%$ knew what should be checked. No one 
had a complete plan of how to develop a web page, while $10.91 \%$ had a partial idea about the steps to be taken to make a good web page.

The number of students tested was rather small, and in our further research we would like to examine a much larger group. It would be good to have more questions referring to different subjects that could be divided in several separate tests. Thus we could obtain more precise results regarding these diverse areas. Students could be grouped according to schools they have finished to compare levels of their prior knowledge.

These results emphasized the necessity to introduce a course called Introduction to web design including the following topics: basic web design ideas, usability, accessibility, privacy and security. In addition courses such as Internet Languages and Tools $1 \& 2$, Applied Databases and Multimedia $1 \& 2$ are essential because of the techniques and technologies used in designing websites that are to be adopted.

Also, courses like Development of the Internet and Marketing and Design, as well as Typography ought to be incorporated in every curriculum tending to cover basic information about the Internet, role of design in marketing activities, and typographic editing of the website's content.

\section{How We Started Our Web Design Study Group}

The Advanced Technical School in Novi Sad has five departments, including the graphic department established ten years ago. It consists of four study groups: graphic engineering, graphic design, web design, and applied photography. Even before the web design group was established, a few students of graphic design took part in the development of the School's site. They were very enthusiastic and successful, and this was actually the reason that determined the faculty and director of the School, PhD B. Nikolić, to open the new study group in 2004.

All principles of the Bologna Declaration were taken into account in creating the curriculum and syllabus for the group, but will not be discussed herein as they can be found in The Bologna Declaration (2000). This document was signed in June 1999 by ministers of education from about 30 European countries. Its main goal is to create a European space for higher education, in order to enhance the employability and mobility of citizens, and increase the international competitiveness of European higher education. The way to promote the student mobility is the European Credit Transfer System (ECTS) designed as a unique system enabling comparison of various educational programs in higher education. It is based on credits that express student workload required to achieve the objectives of a program (60 credits per academic year, 30 per semester) and every individual course within the program.

Our freshmen have different levels of prior knowledge because secondary schools in our country differ significantly regarding their curriculums, syllabuses and equipment. The courses studied in the web design group offer an extensive knowledge of computer science, since modern technologies are widely used in designing. In the first academic year the courses from the computer science area are tailored to provide the students with the basic information about computer uses, as well as word processing (Word), making presentations (PowerPoint), drawing (Corel Draw), and image editing (Photoshop). In this way they get fundamental knowledge in the fields necessary for their further education. During the second year several specialized courses are added introducing the students into the creative process of making websites. Art courses are evenly distributed throughout the first two years of the learning process since web design has its artistic component as well. In the last, third year the fifth semester is almost exclusively reserved for specialist courses dealing with web design. According to the Bologna Declaration all courses last one semester, and students' knowledge is periodically evaluated through tests, essays and examinations. The final mark is a combination of results achieved in all segments of their activities. 
The final, sixth, semester is mainly used for practical assignments and work experience. The former include updating and redesigning of our official website, making presentations for the School, production of video materials for conferences organized by our School, etc. Work experience is gained in companies dealing with IT (Internet providers, software companies, TV stations, advertising agencies, publishing companies, etc.) where students can apply their knowledge and learn how such businesses function. Although all faculty members serve as advisors, in the last semester students are assigned to a faculty member who can help them with practical work. The final examination consists of a written paper prepared on a topic suggested by the student, and its public presentation. The chosen topic refers to issues studied in specialist courses and must be approved by head of the graphic department and one member of the faculty, who becomes the student's mentor. The paper and the presentation are assessed by a commission.

We regularly adapt the curriculum and syllabus to provide our students with the knowledge and skills they need, and also inform them about the most up-to-date equipment and applications, and the latest trends in the world of web design. A balanced combination of theory and practice is essential in studying web design. Only those who manage to combine these two things can become good web designers. At the end of their studies our students receive the Bachelor of Engineering degree in Graphics - Web Design. The satisfactory completion of 180 ECTS credits is required for this undergraduate degree.

Web Design Curriculum

First Year

\begin{tabular}{|c|c|c|c|}
\hline \multicolumn{4}{|c|}{ Semester 1} \\
\hline & Courses & Credit & l+ae+le \\
\hline 1 & Sociology & 3.5 & $2+1+0$ \\
\hline 2 & Form and Style & 4 & $3+0+0$ \\
\hline 3 & $\begin{array}{l}\text { Technical Drawing \& } \\
\text { Descriptive Geometry }\end{array}$ & 6.5 & $2+3+0$ \\
\hline 4 & Computers & 6 & $1+0+3$ \\
\hline 5 & $\begin{array}{c}\text { English } 1 / \text { Specialist } \\
\text { English }\end{array}$ & 3.5 & $1+1+0$ \\
\hline 6 & Drawing and Painting & 6.5 & $1+0+4$ \\
\hline & Summary & 30 & 22 \\
\hline
\end{tabular}

\begin{tabular}{|c|c|c|c|}
\hline \multicolumn{4}{|c|}{ Semester 2} \\
\hline 1 & $\begin{array}{c}\text { Applied } \\
\text { Photography }\end{array}$ & 5 & $2+0+2$ \\
\hline 2 & $\begin{array}{c}\text { Marketing and } \\
\text { Design }\end{array}$ & 4 & $3+0+0$ \\
\hline 3 & $\begin{array}{c}\text { Irae+le } \\
\text { a week }\end{array}$ \\
\hline 4 & $\begin{array}{c}\text { Development of } \\
\text { the Internet }\end{array}$ & 5 & $2+0+4$ \\
\hline 5 & $\begin{array}{c}\text { Operating Systems } \\
\text { Crapn } 1\end{array}$ & 5 & $2+2+0$ \\
\hline 6 & $\begin{array}{c}\text { Computer } \\
\text { Graphics }\end{array}$ & 6 & $1+0+2$ \\
\hline & Summary & 30 & 24 \\
\hline
\end{tabular}




\section{Second Year}

\begin{tabular}{|c|c|c|c|}
\hline \multicolumn{4}{|c|}{ Semester 3 } \\
\hline & Courses & Credit & $\begin{array}{c}\text { I+ae+le } \\
\text { a week }\end{array}$ \\
\hline 1 & $\begin{array}{c}\text { Introduction to Web } \\
\text { Design }\end{array}$ & 5.5 & $2+0+2$ \\
\hline 2 & Typography & 6.5 & $3+0+3$ \\
\hline 3 & $\begin{array}{c}\text { Internet Languages } \\
\text { and Tools 1 }\end{array}$ & 6.5 & $3+0+3$ \\
\hline 4 & Database Systems & 5.5 & $2+2+0$ \\
\hline 5 & Graphic Design 2 & 6 & $2+0+2$ \\
\hline & Summary & 30 & 23 \\
\hline
\end{tabular}

\begin{tabular}{|c|c|c|c|}
\hline \multicolumn{4}{|c|}{ Semester 4 } \\
\hline & Courses & Credit & $\begin{array}{c}\text { 1+ae+le } \\
\text { a week }\end{array}$ \\
\hline 1 & Graphic Design 3 & 6 & $2+0+3$ \\
\hline 2 & Multimedia 1 & 6 & $3+0+2$ \\
\hline 3 & $\begin{array}{c}\text { Networks and Dis- } \\
\text { tributive Systems }\end{array}$ & 6 & $3+2+0$ \\
\hline 4 & $\begin{array}{c}\text { Applied Databases } \\
\text { Internet Languages } \\
\text { and Tools 2 }\end{array}$ & 6.5 & $2+1+2$ \\
\hline 5 & Summary & 30 & 24 \\
\hline
\end{tabular}

\section{Third Year}

\begin{tabular}{|c|c|c|c|}
\hline \multicolumn{4}{|c|}{ Semester 5 } \\
\hline \multicolumn{2}{|c|}{ Courses } & Credit & $\begin{array}{c}\text { 1+ae+le } \\
\text { a week }\end{array}$ \\
\hline 1 & Management & 6 & $3+2+0$ \\
\hline 2 & Multimedia 2 & 6 & $3+0+2$ \\
\hline 3 & Web Communications & 6 & $2+0+3$ \\
\hline 4 & E-Business & 6.5 & $3+0+2$ \\
\hline 5 & Elective course & 5.5 & $\ldots$ \\
\hline & Summary & 30 & $20+\ldots$ \\
\hline
\end{tabular}

\begin{tabular}{|c|c|c|c|}
\hline \multicolumn{4}{|c|}{ Semester 6 } \\
\hline \multicolumn{2}{|c|}{ Activities } & Credit & $\begin{array}{c}\text { I+ae+le } \\
\text { a week }\end{array}$ \\
\hline 1 & Practice at School & 8 & $0+4+4$ \\
\hline 2 & Work experience & 10 & $0+0+12$ \\
\hline 3 & Final examination & 12 & 4 hours \\
\hline & Summary & 30 & 24 \\
\hline
\end{tabular}

Legend: I+ae+le (lectures + auditory exercises + laboratory exercises)

\section{Electives:}

Digital Photography $(2+0+2)$

Quality Management $(2+2+0)$

Introduction to Graphic Technology $(2+2+0)$

\section{Recommendations}

Due to the globalization of Web use nowadays, there is a growing need for specialists in the field of information technology. People have realized the importance of IT careers. Short courses are organized offering training and quick specialization in various IT areas, but there is also a need for systematic and thorough educational programs that provide students with much wider knowledge. Therefore, the starting of the new study group for web design at the Advanced Technical 
School was a step in the right direction. Students have shown a great interest in this branch of design, and our main objective is to educate well-rounded specialists. If they know all about the basic topics regarding different web issues and technologies, student web designers should be able to solve problems they will meet with as professionals.

We think that it is very important to study what freshmen know before setting up a study group in order to select and create appropriate courses. This is necessary to avoid possible mistakes and rewriting of newly accepted programs. Also, we believe that designers educated on a combination of technical and art courses will significantly raise the quality of design on the Web, as both practical and aesthetic sides are included.

The analysis of accessibility and privacy on the Web, and the specialized courses with their descriptions presented in this paper could serve as guidelines in writing similar curriculums and syllabuses. Since the future brings new technologies and web issues, it is good to revise these documents from time to time. For that purpose, curriculum planners ought to be well-informed about the current situation regarding all aspects of the Web.

\section{Conclusion}

Our research, carried out to identify the prior status of students' knowledge of web issues related to web design, was extremely useful in preparing the program for the web design study group. The obtained results gave us a real picture of their insight into the most important questions in this area. In this way we were able to create a suitable curriculum and offer a syllabus with the right content.

In the first year there are courses that introduce students to the world of computing. We insist on all elements that include graphic design and its usage on the Internet. The second year is reserved for the knowledge and skills referring to Internet tools, databases, web design and multimedia. The courses taught in the fifth semester deal with business aspects of web design and its application in different fields. The sixth semester prepares students for the practical implementation of their theoretical knowledge through assignments and work experience in various companies.

We are planning to proceed with our research of certain important web issues in practice. But this time we would like to include a few students in the research team.

\section{References}

Adaptive Computer Technology Training Center (1999), Retrieved March 3, 2003, from http://www.ec.gc.ca/act-tia/

AEB Web Security Guidelines. (2002).Alliance for Electronic Business. U.K, http://www.intellectuk.org/download.asp?file $=138$

The Bologna Declaration. (2000). On the European space for higher education: An explanation. Retrieved November 9, 2004, from http://europa.eu.int/comm/education/policies/educ/bologna/bologna.pdf

ISO 1799 standard. (2000). Retrieved May 10, 2005, from http://www.iso-17799.com

Krunic, T., \& Ruzic-Dimitrijevic, Lj., (2005). E-business and information system securing. Infotech 2005.

McFadden, D., \& Katagiri, G. (2003). Implementation policy and procedures for securing networked devices. Econometrics Laboratory \& Department of Economics, University of California, Berkeley.

Microsoft. (2005). Understanding cookies. Retrieved May 26, 2005 from http://www.microsoft.com/resources/documentation/windows/xp/all/proddocs/enus/sec cook.mspx?mfr=true

New Viruses - They are Hot and Bad. (2005). Retrieved May 20, 2005 from http://www.macnet.com/221482.page 
Nielsen, J. (2003). On usability and web design. Retrieved June 2004 from http://www.useit.com

P3P 1.0, A New Standard in Online Privacy, (2003). Retrieved August 7 from http://www.w3.org/TR/P3P/

Powell, T. A., (2000). Web design: The complete reference. MacGraw-Hill.

Statistics about visually impaired people in EU. (1994). Retrieved September 17, 2004, from http://www.euroblind.org/fichiersGB/statGER.htm

U.S. Census Bureau. (1997). Americans with disabilities. Retrieved June 15, 2004 from http://www.census.gov/prod/2001pubs/p70-73.pdf

U.S. Department of Health and Human Services. (2002). User security guidelines. Retrieved May 22, 2005, from http://www.hhs.gov.familyhistory/downloads/UserSecurityGuidelines.doc

Vulnerabilities, Incidents and Fixes, (2005). Retrieved from http://www.cert.org/nav/index_red.html

W3C. (1999). Web content accessibility guidelines. Retrieved October 15, 2004 from http://www.w3.org/TR/WCAG10

W3C. (2000). Curriculum for web content accessibility guidelines. Retrieved September 10, 2004 from http://www.w3.org/WAI/wcag-curric

W3C. (2005). What is Web Accessibility? Retrieved from http://www.w3.org/WAI/intro/accessibility.php

Web Accessibility in Mind (WebAIM). (1998). Introduction to Web accessibility. Retrieved April 23, 2004 from http://www.Webaim.org/info/intro

Web Guidelines. (2005). Retrieved December 5, 2005, from http://www.cabinetoffice.gov.uk/egovernment/resources/handbook/introduction.asp

Web beacon. (2003). Retrieved June 15, 2005 from www.webopedia.com/TERM/W/Web beacon.html

Web usability - the main rules. (2004). [In Croatian. The original title is Usability sajta - osnovna pravil. No English version available). Retrieved January 2005 from http://www.netnovinar.org/netnovinar/dsp_page.cfm?pageid=437\&articleid $=957 \&$ urlsectionid $=1375 \&$ specialsection=ART_FULL

Why Implement P3P? (2002) Retrieved July 15, 2004 from http://p3ptoolbox.org/guide/section1.shtml

Wolley S., \& Young, B, (2001). Information security - Solutions for information security risk management. Ernst\&Young.

\section{Additional Sources}

Curtin University of Technology, Perth, www.curtin.edu.au

Harvard University, www.harvard.edu

Indiana University, Bloomington, www.indiana.edu

Prirodno-matematicki fakultet (Faculty of Mathematics and Natural Sciences), Novi Sad, www.pmf.ns.ac.yu

The University of Manchester, www.manchester.ac.uk

University of Prince Edward Island, Charlottetown, www.upei.ca

Yale University, New Haven, www.yale.edu 


\section{Appendix 1}

\section{Test on Students' Prior Knowledge}

1 . The main aspect of web design is represented by
a) web content
b) web technologies
c) visual elements
d) purpose of a website
e) purpose, content, techniques and visual elements
f) animations

2. To create a good website it is recommended to use the latest version of XML, DHTML, CSS, etc.
a) Yes
b) No

3. The vertical scroll bar should be
a) short
b) long
c) its length is totally unimportant

4. On a web page there should be
a) at least 10 hyperlinks
b) at least 7 hyperlinks
c) not more than 7 hyperlinks
d) less than 4 hyperlinks

5. To keep the visitor's attention, it is good to use as many interesting advertising banners as possible.
a) Yes.
b) No.

6. Messages like "The picture is loading, please wait",

a) keep the visitor's attention

b) irritate the visitor even more than waiting itself

7. The navigation system of a well-designed website is supposed to be
a) original
b) dynamic
c) simple
d) unusual

8. When designing a website, one should

a) respect the conventions of the traditional graphic interface

b) avoid stereotypes

c) introduce original solutions to surprise visitors

9. User-oriented web design means a) designing according to the client's desires

b) designing a company intranet

c) designing according to the visitor's desires

d) designing for a small group of users 10. Define the steps you would take in creating a website.

11. A website has been designed. Specify what should be verified before its publishing.

12. Accessible design means

a) access to a website without using passwords

b) access to a website over cable Internet

c) making a website accessible for people with special needs

d) a website is easy to find with a search engine

13. Assisting technologies are

a) Java Script, CSS, DHTML

b) screen readers and head pointers

c) cable Internet and Ethernet

d) digital photo cameras and web cameras

14. Security policy is

a) physical securing of a room with a web server

b) material satisfaction in case of information loss from a web server

c) a set of rules to be observed by workers in an institution in order to secure its information system

d) a set of antivirus programs for a web server 
15. A feedback-call system is used to

a) collect user opinions about a website

b) send fax messages over the Internet

c) secure employees' access to their company network

16. Write what you know about P3P.

17. What is the full name of the $\mathrm{W} 3 \mathrm{C}$ ?

18. Marking hyperlinks only with blue is
a) very useful
b) not allowed
c) a stereotype

19. Remote access to a company network

a) is an advantage for the company

b) should be prevented if there is no real reason for its use

c) brings big profits to the company

d) is expensive to operate

20. A website in which one can do anything with maximum 3 mouse clicks

a) is badly structured

b) is a good website

c) is very boring to its visitors

21. Detailed explanations under every picture in a website

a) are very important

b) irritate visitors

c) make no sense since everybody can see what's in the picture

22. Mark the good combinations of text (T) and background (B) colors with + , and the bad ones with -

T: light violet / B: dark violet

T: grey-blue / B: pink
T: violet / B: white

T: light violet / B: light grey

$\mathrm{T}$ : violet / B: white

T: white / B: pink

23. If there are a lot of hyperlinks on a web page, it is useful
a) to group them
b) to arrange them evenly
c) to form a row or a column

24. EventViewer is used to monitor
a) system events in the computer
b) events on a chat page
c) the visitors' book
d) the number of visitors

25. A useful website is

a) any website which makes profit

b) a website used for doing business

c) a website that makes more money than has been spent on its creation

26. Information about the navigation through the website
a) irritates visitors
b) keeps visitors from leaving the web- site disappointed
c) can be helpful to beginners

27. Information travels over the Internet

a) directly from the sender's computer to the receiver's computer

b) directly on the relation sender provider - receiver

c) on the relation sender - about ten other locations - receiver

28. In order to prevent a hacker's attack on a computer, it is useful to
a) update Windows regularly
b) avoid emailing
c) install antiviral software 


\section{Appendix 2}

\section{Web Design Syllabus}

\section{Specialized IT Courses}

Computers - Computer development. Hardware components. Operating systems. Text processors. Presentation software. Photo editing software - digital imaging software. Tools: Word, PowerPoint, Photoshop, etc.

Computer graphics - Principles and tools of interactive computer graphics. Object modeling, two- and three-dimensional transformations. Coloring and illumination models. Tools: CorelDraw, FreeHand, etc.

Operating Systems - Major concepts of modern operating systems. Process management, memory management, and file systems. Architectural support, security, and design. Implementation of some components of a simple operating system.

Development of the Internet - History and development of the Internet. Access to Internet, browsers, etc. Websites with improved usability and accessibility. Internet services: protocols, email, news group, Net meeting, chatting, etc. Advantages and disadvantages of popular search engines and how they perform collecting and indexing of websites. Hazards on the Internet (viruses, spam, worms, hoaxes, and scams), and tips for safer computing. Practical assignment: creating of simple websites.

Introduction to Web Design - Basic concepts of web design. Usability and usability errors in websites. Web developing models. Waterfall and the joint design application models. Web design planning: website's purpose, specification, creating user profiles, creating website prototypes, quality testing, etc. User-oriented web design. Classification of users and needs of specified user groups. User opinion analysis and basic user characteristics affecting web design (sight, memory, patience, etc.). Accessible design, W3C accessibility guidelines, and use of automatic accessibility checking software. Website classifications. Different website structures and web design approaches. Website publishing and updating. Methods of website popularization. Web server performances. Security issues: attacks by hackers and viruses, security polices, and information backup. Secure pages, client certificates, firewalls, security events tracking, etc. System recovery after a virus attack.

Internet Languages and Tools 1 - Hypertext markup language (HTML) syntax. Document type definition. Creating web pages, adding pictures and textual and graphic hyperlinks through HTML. Background pictures. Use of special characters, lists and tables. Table formatting and manipulating. Cascading Style Sheets, (CSS) for text formatting and other manipulations. Java Script for creating interactive navigation commands and animations. Cookies and their placement on the visitor's hard disk. Simple HTML forms. Hidden fields. Java Script manipulations such as submitted data verification, and securing from accidental erasing of form elements by the visitor.

Database Systems - Database concept and history. Logical and physical organization of data, database models, and data independence. Relational databases concepts. Some familiar databases. Embedding database languages in general programming languages.

Internet Languages and Tools 2 - Navigation, searching, text, web graphics, interactive elements, and web technologies issues. Frames, cookies, sub windows, and web page arrangement and navigation issues. Simplicity and consistence of navigation systems. Search facilities, maps, indexes, and site help systems. Web colors and image optimization. Different monitor types and 
their influence on the web page design. Macromedia Fireworks (web graphics), Macromedia Flash (animation), and Macromedia Dreamviewer (web page development).

Applied Databases - Databases for the Web. MySql for database creating and updating. PHP. Connecting websites to MySql driven databases. Web application data errors and error reports. Sessions and their manipulations. Client identification and database security.

Multimedia 1 - Web design and other multimedia. Sound, video and animation in websites. Audio and video technology and digital signals. The Internet possibilities. Interactive tools: customized e-mail inquiry, guest book, chat, etc. Mailing lists and domain registration. Web and mail hosting. Dynamic animations.

Networks and Distributive Systems - Computer network - concept and architecture. Network protocols. Network operating system. Network protection. Designing of computer networks. Web servers.

Multimedia 2 - Web design and redesign. Advertising possibilities: designing and making banners on the Internet, designing company profiles including logos, letter papers, business cards, etc. Marketing and advertising brochures and other publications. Various uses of multimedia in business, education, entertainment, industry and other areas.

Web communications - The Web in media. Media in web design. Practical web design assignments.

E-Business - B2B, B2C. Virtual corporations, web databases, e-commerce, product catalogues, and virtual customer basket. Payment in e-commerce. Security aspects of e-commerce. EDI and EDIFACT. E-banking, e-marketing, e-auctions, and e-advertising. Open source software for ebusiness development: PHP, MySql, and Apache.

\section{Art Courses}

Form and Style - Art and society: topics, forms, and ideas. Form and style changes in the history of painting. Two-dimensional formatting of a composition - concept. Graphic designers and art directors. Forms and styles in graphic arts - graphic design. Works of art of famous artists.

Drawing and Painting - Materials and elements of drawing and painting. Proportions. Shade. Perspective. Composition. Space. Colors and hues. Contrast. Gradient. Rhythm. Form and content.

Applied Photography - Marketing communication rules. Visual communication photography in the $21^{\text {st }}$ century and its place in graphic design. Photograph - text relation. Information, innovation and development of media. Digital imaging and its implementation in printed media and websites.

Marketing and Design - Marketing strategy. Market research. Target groups and competition. Sales psychology. Propaganda messages. Idea in advertising. Advertisements. Creative concept.

Graphic Design 1 - Main characteristics of graphic design. Graphic design in relation to graphics, materials, marketing, production, and transportation. Current trends in graphic design. Trade mark: positive, negative, contour line, color, size, and typography. Logotype: positive, negative, contour line, and color. Design solution and advertising. CD covers and labels.

Graphic Design 2 - Elements of visual identity. Theory of form with art elements: composition, problem definition, and possible solutions. Business cards and labels.

Graphic Design 3 - Posters: theater, film, music, and exhibition Specific posters: ecology, politics, and world peace. Billboard. Constituent elements of visual identity. Theory of form with art elements. 


\section{Survey of Other Courses}

Sociology - Development and methods of sociology. Social groups. Cultural phenomena. Labor Sociology. Global social changes and environmental crises.

Technical Drawing and Descriptive Geometry - Orthogonal projection. Oblique projection. Transformation and rotation. Perspective. Shades. Nets of objects. Special views. Computer graphics in technical drawing.

English 1 - A course in General English (elementary level).

Specialist English - A lower-intermediate course in IT English. Topics include basic computer uses, applications, desktop publishing, image editing, reviewing websites, web page design, multimedia, e-commerce, chat rooms, computer programming, videoconferencing, Netiquette, careers in IT, etc.

Typography - Origins and development of alphabet. Fonts. Typography (formatting). Calculation: text, proofreading, form, and number of pages. Word processors and typography. Business cards and invitations. Typography of books and newspapers.

Management - Economic business. Price policy. Marketing. Market research. Analysis. Management methods and functions. Project management, production, stocks, equipment, and distribution.

Quality Management - Quality system. Company identity. Control and measurement. Control cards. Corrections diagram. Automated quality management.

Digital Photography - Digital record system in photography. Technology of digital image processing. Digital cameras. Digital laboratories. Image-editing software.

Introduction to Graphic Technology - Printed media and information. Basic products of graphic technology: books, magazines, newspapers, posters, brochures, and printed packaging. Basic materials. Designing of graphic products. Manufacturing.

\section{Biographies}

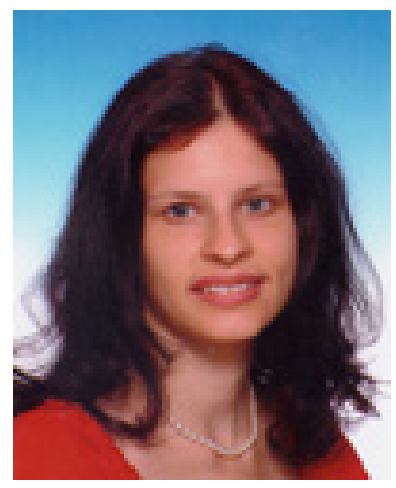

Tanja Krunić is a lecturer at the Advanced Technical School, Novi Sad, Serbia. She teaches courses in web design and Internet languages and tools. She holds a MS in mathematics and is currently working towards her PhD in Numerical Analysis from the Faculty of Mathematics and Natural Sciences, Novi Sad. Her research interests include important issues like usability, accessibility, privacy, and security on the World Wide Web. She is a co-author of E-business and Information System Securing, Infotech 2005; How to Teach Mathematics in Special Circumstances, PRIM 2004; and the first author of E-commerce and User Privacy in Serbia and Montenegro, The 6-th International Conference on Electronic Commerce and Electronic Business, Palic 2006; Accessibility of E-commerce Websites in Serbia and Montenegro, The 6-th International Conference on Electronic Commerce and Electronic Business, Palic 2006. 


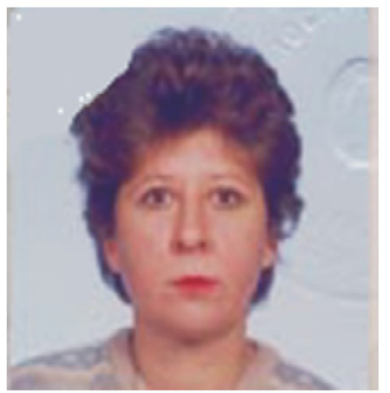

Ljiljana Ružić-Dimitrijević is a professor at the Advanced Technical School, Novi Sad, Serbia. She teaches courses in computers, computer graphics, and development of the Internet. She got her MS degree in mathematics at the Center of Multidisciplinary Studies, Belgrade in 1991. Her field of expertise is graphics in web design. She is head of the graphic department.

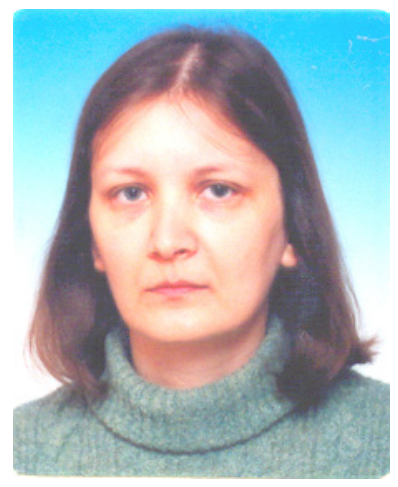

Branka Petrović is working as a lecturer at the Advanced Technical School, Novi Sad, Serbia. She holds a BA in English and Literature from the Philosophy Faculty, Novi Sad and teaches courses in general English and English for special purposes. She is particularly interested in developing additional teaching materials.

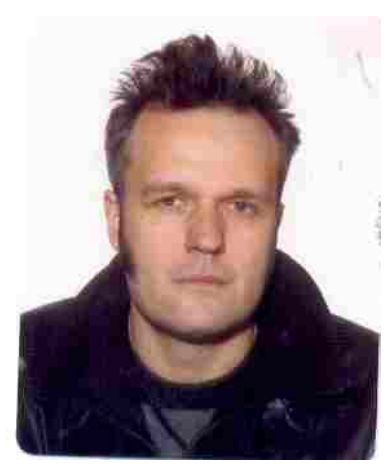

Robert Farkaš is a senior lecturer at the Advanced Technical School, Novi Sad, Serbia, where he teaches courses in graphic design, multimedia and web communications. He graduated from the Art Academy, Novi Sad and attended the Workshop in New Media at Trans-MediaAkademie Hellerau, Dresden, Germany. He participated in several international projects and exhibitions (EIGEN ART, Munich, ARTEXPO, Budapest, Europ*Art, Geneve, COMTECart, Dresden, etc). In 2005 he served as director of the GEF (Global European Fields) project for Serbia and Montenegro. 